\title{
Bibliotecários/as em tempos de cibercultura: reflexões sobre atuação profissional e práticas bibliotecárias
}

\author{
Shirlei Galarça Salort I \\ http://orcid.org/0000-0002-2226-8097
}

\section{Isabel Aparecida Bilhão II \\ Daniel de Queiroz Lopes III}

\footnotetext{
I Universidade Federal do Rio Grande do Sul, Porto Alegre, RS, Brasil. Mestre em Educação pela Universidade do Vale do Rio dos Sinos.

${ }^{I I}$ Universidade do Vale do Rio dos Sinos, São Leopoldo, RS, Brasil. Docente do Programa de Pós-Graduação em Educação.

III Universidade Federal do Rio Grande do Sul, Porto Alegre, RS, Brasil. Docente na Faculdade de Educação.
}

http://dx.doi.org/10.1590/1981-5344/3563

Este artigo apresenta parte dos resultados de pesquisa de uma dissertação na qual busca-se aprofundar as reflexões sobre as práticas dos bibliotecários e identificar suas percepções e sentidos sobre a atuação profissional e sobre a biblioteca universitária no contexto da cibercultura. O estudo foi realizado em uma biblioteca universitária da área médica e nele apresentam-se a trajetória e as características dessa biblioteca e identificam-se, com base em entrevistas semiestruturadas realizadas com oito bibliotecárias atuantes ou aposentadas, os sentidos atribuídos às práticas bibliotecárias. Percebe-se nas narrativas uma constante busca por reconhecimento e valorização da profissão, assim como a preocupação em manter a frequência dos usuários ao espaço físico da biblioteca estudada. Dentre as modificações percebidas nessa atuação, nota-se que o sentido de "mediador" passa a dar espaço ao sentido de "educador" e a postura de "esperar o usuário" passa a dar 
lugar a de "buscar o usuário", o que demonstra uma inquietação com relação ao futuro da biblioteca e da atuação do bibliotecário. Assim como identificam-se sentidos que podem indicar estratégias de manutenção da cultura profissional e da permanência no mercado de trabalho.

Palavras-chave: cibercultura, bibliotecas; universitárias, práticas bibliotecárias.

\section{Librarians in times of cyberculture: reflections on professional performance and library practices}

This article presents part of dissertation research results, in which it seeks to deepen the reflections on the practices of librarians and to identify their perceptions and senses about the professional performance and about the university library in the context of cyberculture. The study was carried out in a university library of the medical area and in it, the trajectory and the characteristics of this library are presented and the meanings attributed to the librarianship practices are identified, based on semistructured interviews with eight active or retired librarians. In the narratives a constant search for recognition and appreciation of the profession, as well as the concern to maintain the frequency of the users to the physical space of the studied library. Among the perceived modifications in this performance, it is noticed that the sense of "mediator" gives way to the sense of "educator" and the "waiting for the user" posture starts to "seek the user", which shows a concern about the future of the library and the work of the librarian. As well as, we identify meanings that can indicate strategies of maintenance of the professional culture and the permanence in the job market.

Keywords: cyberculture, university libraries, library; practices.

\section{Introdução}


Este estudo se insere em um campo de reflexão bastante vasto, pois há algum tempo bibliotecários e estudiosos vêm dicutindo qual o futuro das bibliotecas tradicionais e da profissão de bibliotecário, a partir do crescente uso de suportes digitais de informação propostos pelas tecnologias de informação e comunicação, nas chamadas "sociedade da informação" e "sociedade do conhecimento". Influenciam nesse contexto as transformações ocorridas nos modos de pesquisar e ler no ambiente acadêmico em tempos de cibercultura, que impactam tanto as universidades, quanto as suas bibliotecas acadêmicas e as práticas dos profissionais bibliotecários que nelas atuam. Conforme Nunes e Carvalho (2016, p. 179) "as bibliotecas universitárias são instituições de ensino superior e estão voltadas para atender as necessidades de todos os membros da comunidade acadêmica da qual fazem parte" e "com o intuito de agir interativamente para ampliar o acesso à informação e contribuir para a missão da universidade".

De acordo com Cunha (2000), prevendo o futuro das bibliotecas universitárias há mais de uma década, o contexto da cibercultura pressupõe a necessidade de os bibliotecários que atuam nas bibliotecas universitárias repensarem suas práticas, tendo em vista não apenas as constantes transformações introduzidas pelas tecnologias de informação e comunicação em suas atividades diárias, mas principalmente as mudanças ocorridas nos modos de ensinar e aprender nas universidades. Somandose a isso, é preciso que a biblioteca universitária não só atenda satisfatoriamente as necessidades de informação da sua comunidade acadêmica, como também contribua para a geração do conhecimento, atuando para a formação pessoal e profissional, a fim de não correr o risco de não ser reconhecida como uma instituição necessária:

No caso da biblioteca universitária, é necessário examinar as enormes possibilidades do futuro e entender que o desafio mais crítico será remover os obstáculos que a impedem de responder às necessidades de uma clientela em mudança, transformar os processos e estruturas administrativas que caducaram e questionar as premissas existentes. Aquela biblioteca que der um passo nesse processo de mudança irá renascer. As outras que, à semelhança de um avestruz ameaçado, enterrarem suas cabeças na areia, defendendo rigidamente o status quo, ou, o que é pior, conservarem alguma visão idílica do passado, correrão grande risco e terão pouca chance de serem reconhecidas como instituições necessárias. (CUNHA, 2000, p.88).

Neste cenário, surgem muitos questionamentos, dentre eles: como os bibliotecários estão percebendo e repensando as suas práticas profissionais diante das constantes transformações impostas pela cibercultura no ambiente das bibliotecas universitárias? Suas percepções estão alinhadas com a literatura da área? Nota-se que tanto no campo da 
Ciência da Informação quanto no da Educação, pouco se discute sobre a visão dos próprios bibliotecários no que concerne às suas práticas nas bibliotecas universitárias e ao futuro dessas instituições em tempos de cibercultura.

Indicativo disso é o fato de que ao realizarmos uma consulta preliminar aos bancos de artigos, teses e dissertações, na Scielo e no Google Acadêmico, combinando os seguintes descritores: biblioteca(s), bibliotecário(s), "and" sentido(s), significado(s), práticas e cibercultura, não foram encontrados artigos ou trabalhos específicos discutindo os sentidos atribuídos às práticas bibliotecárias pelos profissionais da área. Apenas alguns trabalhos se aproximaram desta temática, dentre eles dois artigos sobre os sentidos atribuídos às bibliotecas escolares (FERRAREZI; ROMÃO, 2008) e (FERRAREZI; ROMÃO, 2013), duas dissertações sobre representações sociais a respeito da profissão de bibliotecário (RESENDE, 2005) e (NITSCHKE, 2008) e uma dissertação sobre o discurso de bibliotecárias que atuam na área médica (CRESTANA, 2002). Diante desse panorama, entendemos como justificável a proposta desse estudo que, embora realizado em uma biblioteca universitária específica, pretende contribuir para a ampliação do dialogo sobre as percepções dos bibliotecários acerca de suas práticas no contexto da cibercultura1.

Nessa direção, os objetivos desse artigo são: analisar as percepções das bibliotecárias entrevistadas que atuam em uma determinada biblioteca universitária da área da saúde e identificar sentidos com relação à trajetória e atuação profissional e às práticas bibliotecárias em tempos de cibercultura. $O$ estudo orientou-se por uma abordagem qualitativa, ou seja, procurou observar as implicações de um fenômeno macrológico: a cibercultura, em um contexto específico. A produção de informações embasou-se em entrevistas semiestruturadas realizadas com oito bibliotecárias que atuam ou que já atuaram na biblioteca estudada.

A concepção que orientou a realização das entrevistas foi a de que elas têm um caráter compreensivo. Conforme Nadir Zago, nesse tipo de entrevista a atuação do pesquisador não se "limita à escuta e ao registro de informações, não se reduz à pura manipulação de técnicas nem a um encontro como qualquer outro" (ZAGO, 2003, p. 306). Para a autora, "na pesquisa compreensiva, o pesquisador se engaja formalmente; o objetivo da investigação é a compreensão do social e, de acordo com este, o que interessa ao pesquisador é a riqueza do material que descobre" (ZAGO, 2003, p. 296).

A análise dos dados empíricos embasou-se na noção de que o universo digital, ou ciberespaço, é "[...] um espaço informacional, no qual os dados são configurados de tal modo que o usuário pode acessar, movimentar e trocar informação com um incontrolável número de outros usuários" (SANTAELLA, 2004, p. 45). Como não há um consenso na literatura sobre os sentidos dados ao ciberespaço e à cibercultura, nesse

\footnotetext{
${ }^{1}$ A análise apresentada é parte da Dissertação de Mestrado, intitulada A Biblioteca e o Bibliotecário em tempos de cibercultura: espaços e práticas,2017,defendida junto ao Programa de Pós-Graduação em Educação, daUniversidade do Vale do Rio dos Sinos.
} 
estudo, optamos pela definição de Lúcia Santaella (2004), que trata o ciberespaço como um "espaço informacional multidimensional que depende da interação do usuário, permite a este o acesso, a manipulação, a transformação e o intercâmbio de seus fluxos codificados de informação" (SANTAELLA, 2004, p. 45). Considerando que o ciberespaço é o espaço que se abre quando o usuário conecta-se à rede, ou seja, um espaço feito de circuitos de informação - espaço semântico - a ser percorrido em um universo etéreo que se amplia indefinidamente.

Para Santaella, a navegação nesse espaço propõe diferentes graus de imersão e é nesse sentido que o adjetivo "imersivo" qualifica o novo tipo de leitor, na medida em que se entende "leitor" como aquele que desenvolve determinadas disposições e competências que o habilitam para a recepção e resposta à densa quantidade de signos do mundo, esse leitor especial navega através de dados híbridos (textos, sons e imagens) próprios da hipermídia (SANTAELLA, 2004).

A fim de contextualizar e estimular a reflexão sobre o tema do estudo apresenta-se na primeira sessão uma breve descrição do campo empírico, na segunda sessão as percepções sobre a trajetória e a atuação profissional, observadas nas narrativas das bibliotecárias e, na terceira, reflete-se sobre as concepções e/ou sentidos relacionados às práticas bibliotecárias. Cabe esclarecer que a primeira autora desse artigo é servidora da biblioteca analisada e, portanto, tal fato demandou um contínuo exercício de desnaturalização e de estranhamento do cotidiano, permitindo a formulação de questões e de interpretações que orientaram as reflexões sobre o contexto empírico.

\section{0 contexto empírico}

Os resultados e análises apresentados embasam-se em um estudo realizado em uma biblioteca universitária da área da saúde, a Biblioteca da Faculdade de Medicina da Universidade Federal do Rio Grande do Sul (UFRGS) e do Hospital de Clínicas de Porto Alegre (HCPA), denominada Biblioteca FAMED-HCPA a partir de convênio firmado entre a Universidade e o Hospital no ano de 1990. Entretanto, conforme consta na edição comemorativa referente ao centenário da FAMED: "Fogos de bengala nos céus de Porto Alegre", os primórdios da instituição remontam à aquisição da primeira sede da Faculdade de Medicina e Farmácia de Porto Alegre, em 1898, sendo que a Biblioteca foi constituída no ano de 1900 (HANSSEN; RIGATTO, 1998, p. 49).

A Faculdade de Medicina e Farmácia de Porto Alegre foi a terceira faculdade médica criada no Brasil, o que torna sua Biblioteca uma das primeiras especializadas na área da saúde em âmbito nacional. Atualmente, sua bibioteca integra o Sistema de Bibliotecas da UFRGS, composto por 31 bibliotecas.

No período de realização deste estudo, a Biblioteca contava com 12 servidores técnico-administrativos (seis bibliotecárias e seis assistentes), uma bibliotecária do HCPA e cinco bolsistas. Sendo que às bibliotecárias, 
cabe realizar atividades referentes ao processamento técnico de documentos, à organização de acervos, à gestão da Biblioteca, ao atendimento aos usuários internos e externos à Universidade, presencialmente e por e-mail, aos atendimentos do serviço de Comutação bibliográfica2, à organização e capacitação no uso de recursos de informação e às orientações sobre normalização de documentos.

A atuação da Biblioteca FAMED-HCPA foi significativamente alterada pelas modificações impostas pela cibercultura, pois os formatos digitais produziram alterações significativas nas práticas desenvolvidas nesse ambiente. Atualmente, em bibliotecas universitárias como esta, sem conexão de rede (internet) não é possível trabalhar, pois os acervos bibliográficos estão registrados em catálogos on-line, tornado impossível localizar um livro na estante através de catálogos manuais, pois eles foram extintos. A informação científica, que antes era restrita ao espaço físico das bibliotecas, hoje circula nas redes, o que torna os profissionais dependentes do acesso on-line. Para os profissionais bibliotecários, esta dependência ocorre tanto no desempenho de suas atividades técnicas como no atendimento às demandas dos leitores/usuários, pois, com a cibercultura, surgiram novas práticas de leitura, leitores diferenciados, autônomos e em alguns casos, altamente familiarizados com o uso das tecnologias de informação e comunicação.3 Nesse contexto, também extinguem-se algumas atividades exclusivamente realizadas por bibliotecários, como é o caso da confecção de fichas catalográficas, que hoje podem ser feitas através de programas de computador.

No que se refere às bibliotecas universitárias, ainda se observam práticas bibliotecárias muito voltadas à gestão de recursos (humanos e materiais), de espaços físicos e de acervos, quando talvez se deva pensar em novas práticas profissionais. Diante desse cenário questiona-se: Como o profissional bibliotecário percebe sua trajetória e atuação profissional em tempos de cibercultura? Como suas concepções e sentidos se refletem nas práticas bibliotecárias atuais?

\section{Relatos profissionais e reflexões sobre as práticas bibliotecárias em tempos de cibercultura}

Diante das indagações citadas, analisam-se alguns aspectos apresentados nas entrevistas realizadas com as oito bibliotecárias do quadro de funcionários ativos e inativos da Biblioteca. O objetivo foi

\footnotetext{
${ }^{2}$ Serviço cooperativo que obtém documentos em bibliotecas de outras instituições.

${ }^{3}$ Durante a investigação realizamos um levantamento preliminar com os alunos do curso de graduação em Medicina, utilizando questionário on-line, para identificar se costumavam consultar os bibliotecários em suas questões de pesquisa ou mesmo acadêmicas. Em uma amostra com 43 alunos respondentes, distribuídos nos doze semestres do curso, verificou-se que $51 \%$ dos respondentes nunca haviam consultado um bibliotecário e dos $49 \%$ que disseram que consultaram este profissional, $71 \%$ das consultas foram referentes ao funcionamento da biblioteca.
} 
conhecer as concepções e sentidos atribuídos à atuação profissional e às práticas bibliotecárias em tempos de cibercultura. Contudo, as entrevistas com as funcionárias aposentadas contribuiríam para o entendimento das transformações nas práticas profissionais ao longo dos anos.

Para a constituição da base empírica desse estudo foram entrevistadas seis bibliotecárias atuantes no ano de 2016 e duas bibliotecárias aposentadas, que trabalharam por mais de 20 anos na biblioteca estudada. As narrativas foram construídas com base nas memórias dessas profissionais e, ao trabalhar com elas, deve-se ter em mente que a memória é sempre uma construção realizada a partir do presente, ou seja, "o sujeito é convidado a 'voltar atrás no tempo' e, assim, sua memória inicia uma operação no sentido de reconstruir vivências do passado que hoje considera marcantes" (GRAZZIOTIN; ALMEIDA, 2012, p. 38).

As entrevistas com as bibliotecárias aposentadas ocorreram em suas residências conforme escolha das próprias entrevistadas e tiveram duração de 70 a 95 minutos cada. Já as entrevistas com as bibliotecárias atuantes ocorreram na Biblioteca, também por escolha das entrevistadas e a duração variou de 40 a 70 minutos. Entre os cuidados éticos, definiuse, no momento do convite, que as identidades das participantes seriam mantidas em sigilo, objetivando tanto evitar sua exposição a situações constrangedoras em função de suas ideias e opiniões pessoais, quanto garantir maior fluidez nos diálogos. As entrevistadas foram identificadas como A, B, C, D, E, F, G e H e nas citações literais de suas respostas optou-se por manter a linguagem coloquial, própria da narrativa oral.

As entrevistas semiestruturadas, foram realizadas com base no seguinte roteiro de perguntas:

Conte um pouco de sua trajetória profissional. Como e por que você se tornou bibliotecária? O que a levou a escolher o curso?

Qual é sua opinião sobre a atuação do bibliotecário na comunidade acadêmica? Como acha que ela deve ser atualmente? Qual é a importância do bibliotecário no contexto acadêmico?

Como você percebe a prática do bibliotecário em tempos em que os usuários possuem acesso à informação pela internet?

Conte um pouco sobre sua prática profissional na Biblioteca FAMEDHCPA. Quais mudanças você percebe em suas práticas ao longo do trabalho como bibliotecária?

Tais questões pretenderam estimular relatos sobre trajetória, atuação e práticas profissionais das bibliotecárias e suas relações ao longo dos anos, a fim de compreender as mudanças ocorridas nessas práticas e mapear concepções atuais sobre o futuro da profissão e da biblioteca universitária.

\subsection{Trajetória e atuação profissional}


Em relação às primeiras questões - Conte um pouco de sua trajetória profissional. Como e por que você se tornou bibliotecária? O que a levou a escolher o curso? - somente as bibliotecárias aposentadas afirmaram que tiveram influência de familiares para a escolha do curso. Os relatos apresentados por elas possibilitaram refletir sobre as condições e espectativas de trabalho para as mulheres no período em que realizaram o vestibular, na década de 1970. As depoentes pertenciam a famílias de classe média urbana, nas quais ainda era mais comum que os rapazes e não as moças ingressassem na universidade. A possibilidade aberta pela entrada no curso de Biblioteconomia era então condizente com as noções socias de carreiras aceitáveis para as mulheres.

Os motivos da escolha profissional, citados pelas demais foram: a visita a uma determinada biblioteca despertou o interesse pelo trabalho nesse ambiente, o fato de gostar de ler, desejar ingressar na universidade pública, gostar de frequentar a biblioteca da escola, não se interessar por áreas ligadas às ciências exatas e, ainda, a menor concorrência no vestibular.

Algumas respostas também demonstraram o não conhecimento sobre o curso e, por isso, sua escolha como segunda opção no vestibular. Conforme os relatos abaixo:

Coloquei Biblioteconomia porque entrava pouca gente, aí eu digo vou entrar num curso que tenha poucos candidatos pra poder depois pedir o remanejo. Não sabia o que era Biblioteconomia, caí de paraquedas (Entrevistada F, 2016).

Eu me inscrevi pra Direito na UFRGS em primeira opção que tinha na época, né... e coloquei Biblioteconomia em segunda opção, por gostar de ler. Era esse o meu critério, não sabia direito como era a profissão, não tinha contato com nenhuma bibliotecária, a não ser na minha escola. E depois eu descobri que era uma professora né, não era alguém da área, formada mesmo. Aí fiz o vestibular, até fui bem, não fui tão mal assim, mas não passei pro Direito. Confesso que fiquei frustrada, porque a gente quer passar no que colocou em primeira opção, mas resolvi fazer, eu disse pôxa vida, passei numa universidade federal né, que muita gente quer, vou tentar (Entrevistada C, 2016).

Observando-se que o bibliotecário continua em busca do reconhecimento social e de valorização profissional e que as atividades desenvolvidas por ele ainda não são amplamente conhecidas pela comunidade, incluindo a própria comunidade acadêmica em que trabalha, é compreensível que a graduação em Biblioteconomia não seja, em muitos casos, a eleita em primeira opção. Fraga, Mattos e Cassa (2008, p. 153) consideram que a apatia desse profissional ou a "falta de interesse pelas 
questões do cotidiano de sua atuação", ou o desinteresse por qualificação e atualização contínuas, podem estar relacionadas ao fato do curso de Biblioteconomia não ser o escolhido como primeira opção dos ingressantes na graduação.

No que se refere às entrevistadas que já tinham algum conhecimento prévio sobre o curso de Biblioteconomia, ou que foram influenciadas por familiares e amigos na escolha dessa graduação, observou-se que não hesitaram em elegê-la em primeira opção.

[...] daí eu lembro que naquele momento assim... ele pegou a enciclopédia, se não me engano a Mirador, e pegou o verbete Biblioteconomia e me mostrou o que que era, ali eu conheci o curso de biblioteconomia e comecei a buscar mais informações. Assim... comecei a me interessar e aí o próprio funcionário da biblioteca e outros funcionários, chegou um ponto aí que eles pediam pra eu ajudar os outros alunos na hora do recreio a procurar livros e tal, e aquilo foi me cativando. Eu gostava de ajudar os outros a procurar informação e aí eu fui vendo que isso era uma coisa bem importante dentro da Biblioteconomia, fui me apaixonando e quando eu fui prestar vestibular foi a minha primeira e única opção (Entrevistada E, 2016).

Ah, eu me tornei bibliotecária acho que da influência da minha irmã e eu fiz secretariado. No secretariado a gente já tinha uma cadeira de biblioteconomia e organização de arquivos (Entrevistada G, 2016).

Na maioria das narrativas sobre experiências profissionais passadas houve uma tendência à idealização, ou seja, à descrição seletiva das vivências que foram apresentadas reiteradamente de forma prazerosa. Esse aspecto pode ser observado, por exemplo, nas respostas das Entrevistadas C, E e H:

Foi completamente diferente de tudo o que eu vivi até agora, umas coisas assim uau! né, radicalmente diferente, mas foi muito legal (Entrevistada C, 2016).

Daí eu fui pra uma outra realidade que era uma biblioteca de um banco, então bem especializada assim, nas áreas de Economia, predominava Economia e Direito e foi um período muito legal assim (Entrevistada E, 2016). 
Não teve um dia na minha vida que eu tivesse me questionado se eu tivesse feito um curso errado, era aquilo ali, aquilo me veio assim... como uma inspiração mágica, divina e mágica (Entrevistada $\mathrm{H}, 2016)$.

Esses fragmentos podem ser observados com base nas ponderações de Jorge Larrosa (2004). Para ele, a memória individual não constitui a memória objetiva do passado, pois ela envolve interpretação e construção, buscando dotar de coerência um ponto desde o passado até o presente. Nesse sentido, Grazziotin e Almeida (2012, p. 37) esclarecem ainda que,

[...] toda narrativa oral é, ao menos em parte, autobiográfica, pois quando a pessoa evoca suas memórias exercita uma tentativa de explicar o que pensa que foi, o que pensa que era, desenvolvendo, assim, a construção de uma verdade sobre si mesma. Cada um escolhe o que lembrar conforme o/s lugar/es de sujeito que ocupa.

Portanto, ao privilegiarem a evocação dos aspectos positivos de seu passado profissional e a certeza da trajetória escolhida, essas respostas não podem ser vistas como objetivamente resultantes de vivências livres de embates, tensões e contradições e sim como formas de marcar, no presente, os lugares sociais ocupados pelas profissionais entrevistadas. Especialmente porque esse presente está em profunda transformação, ocasionando dúvidas e inseguranças em relação ao futuro de sua atuação.

Assim, quando questionadas sobre sua opinião acerca da atuação do bibliotecário na comunidade acadêmica e como deve ser essa atuação atualmente, identificam-se nas respostas necessidades de reafirmação da profissão. Elas sugerem uma atuação de promoção e divulgação por parte dos bibliotecários, tanto no que se refere à sua atuação profissional, quanto aos serviços prestados pela biblioteca. O que, possivelmente, estaria relacionado com uma tentativa de justificar sua importância em um contexto no qual as bibliotecas não correspondem mais àqueles espaços quase exclusivos de circulação da informação científica e no qual as bibliotecas precisam garantir o reconhecimento como instituições necessárias, o que vai ao encontro das previsões de Cunha (2000).

Atualmente, os pesquisadores, em muitos casos, não necessitam sair de seus gabinetes profissionais ou de suas residências para terem acesso à informação especializada, pois a internet possibilitou o acesso a tais conteúdos a partir de bibliotecas digitais. Assim, não há obrigatoriamente a necessidade de deslocamento a uma biblioteca física ou a consulta a um bibliotecário. Se observarmos atentamente, também veremos que algumas bases de dados possuem o mesmo padrão de organização de informação e oferecem interfaces on-line intuitivas, contribuindo significativamente para a autonomia dos pesquisadores. 
Cenário que complexifica e torna ainda mais urgente a reflexão sobre novas formas de atuação do bibliotecário.

Diante disso, também foi possível identificar nas narrativas um desejo de consolidar uma imagem profissional diferente daquela relacionada aos estereótipos construídos em torno da profissão de bibliotecário, que o associam à passividade e à reclusão ao interior das bibliotecas. Na resposta abaixo se pode observar um desses apelos à construção de uma postura "ativa":

Ah eu acho que tem que ser bem "cara de pau", (risos), eu vejo aqui, tem que ir atrás dos professores, tem que encher 0 saco da direção pra conseguir fazer as coisas acontecerem né, porque se a gente ficar só aqui dentro esperando as pessoas virem até a gente não vai acontecer nada. Então eu acho que tem que ser... Bibliotecário eu acho que uma das qualidades que tem que ter é isso, ser cara de pau, vender o próprio serviço e mostrar o quanto é importante (Entrevistada $A$, 2016)

Esse aspecto da narrativa pode indicar tentativas de comprovar eficiência e legitimar a profissão a partir de uma concepção que sugere pró-atividade por parte dos bibliotecários, o que se pode verificar a partir das seguintes frases: "ser cara de pau", "vender o próprio serviço" e "mostrar o quanto é importante". Essa última evidencia implicitamente uma busca por legitimação profissional.

Tendo em vista a observação de Nitschke (2008, p. 61), de que "as práticas profissionais do bibliotecário condicionam as representações sociais que os usuários possuem delas", compreende-se o porquê da visão social clássica sobre o bibliotecário ser marcada por estereótipos. Entre esses estereótipos, destacam-se os identificados por Resende (2005), que classificam os bibliotecários como: mulheres, não tão jovem, de óculos cujas lentes mais parecem um fundo de garrafa, com coque no cabelo e, como conduta, o desagradável pedido de silêncio que corta diálogos.

No trecho acima mencionado percebe-se a apropriação de algumas recomendações da literatura corrente para melhorar a imagem profissional. Um exemplo são as proposições de Fraga, Mattos e Cassa (2008) que consideram que, para o bibliotecário alcançar o desejável reconhecimento e valorização, é preciso investimento em difusão da profissão e, para isso, as técnicas de marketing profissional e pessoal e de endomarketing seriam as principais estratégias. Nessa lógica, vêm se consolidando noções defendidas, por Drabenstott e Burmande, desde os anos 1990, de que o bibliotecário deve posicionar-se e criar oportunidades para demonstrar sua importância no manejo com a informação, e não "esperar sentado para que outros profissionais tomem seu posto" (1997, p. 15). 
Outro exemplo da apropriação dessas noções é a indicação de que o bibliotecário deve desenvolver habilidades interpessoais e comunicativas, isso pode ser observado nos dois trechos abaixo, selecionados da narrativa da Entrevistada E:

Então, eu acho que precisa ter um pouco de pró-atividade do bibliotecário, pensando nos relacionamentos com o usuário.

$[\ldots]$

Tu tem que saber interagir com pessoas, eu acho que o bibliotecário... que isso ajuda em qualquer área da vida da gente, se tu não tiver habilidades pra tratar, pra conversar e... e ser um pouco publicitário mesmo... de fazer propaganda daquilo que tu tem. Tenho visto na prática muitos dos serviços que às vezes a gente oferece ou recursos que eles têm na mão pra usar, muitas vezes eles deixam de usar porque não foi feita uma boa propaganda daquilo, vamos chamar propaganda assim (Entrevistada E, 2016).

Essas considerações da Entrevistada E podem ser pensadas a partir das observações de Resende (2005) para quem, "as comunicações e condutas do bibliotecário interferem nos seus interlocutores, elas não são neutras, uma vez que dão forma às relações estabelecidas, pelo que expõem indícios dos complexos campos de representações que aí se polarizam e aglutinam" (RESENDE, 2005, p. 13-14). Tais considerações também se identificam com a concepção de Lankes de que "a maneira mais eficaz de ver a relação com a comunidade não é uma lista de serviços ou de acervos. Também não se consegue isso com estatísticas ou planos estratégicos. É nas conversas que conseguimos vislumbrar todas estas possibilidades" (LANKES, 2012, não paginado). Nesse sentido, infere-se também que a partir das conversas é possível conquistar ou reconquistar determinados espaços.

$\mathrm{Na}$ passagem abaixo, selecionada da narrativa apresentada pela Entrevistada $\mathrm{H}$, constata-se tanto uma perda de espaços profissionais, quanto indica as possíveis formas de reconstituição desses espaços:

Eu acho que talvez tu não tenha mais aquele papel tão representativo como tinha, mas se tu faz esse papel ainda de que tu é um elemento que conduz pra os caminhos, eu acho super importante... em tempos em que informação é o que mais tem por aí, em tempos que a internet... quanta gente que tem informação completamente enlouquecida, errada, porque pega na internet? A internet aceita tudo né? (Entrevistada H, 2016). 
Nesse trecho também se pode observar uma mudança de sentido atribuído à atuação que vem se constituindo em uma nova justificativa e/ou perspectiva para o bibliotecário: sua função educacional. Embora esta ainda se apresente de forma difusa e pouco articulada ao cotidiano de trabalho, nota-se o crescimento, no contexto acadêmico, da necessidade de que esse profissional assuma ações formativas para o uso da informação, especialmente dos usuários iniciantes no ambiente de pesquisa, ou seja, dos jovens acadêmicos dos cursos de graduação.

Assim, observa-se em algumas narrativas a perspectiva de mudança de sentido no que tange à atuação do bibliotecário. De uma noção de intermediário entre informação e usuário estaríamos estabelecendo uma visão de "bibliotecário educador", ou seja, não mais aquele que só transmite a informação, mas aquele que atua para a geração do conhecimento, ou ainda, que interfere no desenvolvimento cognitivo de seu interlocutor.

Conforme a Entrevistada C:

O bibliotecário faz parte do processo de educação, isso com certeza, seja orientando especificamente no uso de bases de dados, de ferramentas e tal, ele acaba tendo um pouco de educador nesse contexto nosso assim, da educação mesmo, universitária (Entrevistada C, 2016).

A Entrevistada B acrescentou que, além de o bibliotecário posicionar-se como um intermediário entre a informação e o seu usuário, é preciso que ele planeje novos serviços de informação e a inserção de novas tecnologias nas bibliotecas:

Então... realmente, como intermediário entre a informação e esse usuário ele deve ir se desdobrando entre o planejar, pensar em serviços novos, ofertar o que tem de mais novo, não só em acervos, mas também de tecnologia (Entrevistada B, 2016).

Resende (2005, p. 49), também apontou que "na prática profissional em ambiente universitário é possível perceber a relevância da prática educativa do bibliotecário". Esta deverá ser pensada a partir de uma formação pedagógica e de uma nova fase na profissão. Conforme essa autora:

Em certo sentido, portanto, tal qual professores, os bibliotecários transmitem informação e a problematizam. Esta prática acontece independente do currículo do curso, ainda que devamos admitir que uma formação pedagógica poderia 
contribuir, de forma talvez decisiva, para uma performance de qualidade deste profissional. Pensar o bibliotecário como educador, na perspectiva aqui definida, seria uma nova fase da evolução desta profissão no presente século. (RESENDE, 2005, p. 48).

Tais considerações de Resende propõem novos caminhos para os bibliotecários que atuam nas universidades, sugerindo a ocupação de novos espaços e o desenvolvimento de outras práticas profissionais, pois, em tempos de cibercultura, a tutoria no uso da biblioteca e de outros recursos de informação deve ir além do espaço físico da biblioteca. Num sentido semelhante, Belluzzo (2005, p. 38) também defende que a integração entre professores e bibliotecários é fundamental para que a biblioteca possa contribuir para o que chama de "excelência educativa na sociedade contemporânea".

Quanto à questão: Qual importância do bibliotecário no contexto acadêmico? As entrevistadas consideraram que todas as atividades desempenhadas pelo bibliotecário são importantes, principalmente, as de organização da informação e defenderam que tais atividades atuam como suporte para o bom atendimento ao usuário. Elas ressaltaram também como importância do bibliotecário no contexto acadêmico, a atuação como "mediador", ou seja, como "elo" de ligação entre informação e demanda. Como se pode observar no seguinte trecho do relato da Entrevistada E:

Eu acho que o bibliotecário, seja qual for sua área de atuação, é extremamente importante numa instituição, especialmente falando em uma instituição de ensino, porque é o bibliotecário que vai fazer o elo com o usuário, que aí envolve professores, direção, alunos de graduação, de pós-graduação (Entrevistada E, 2016).

Porém, a visão mais tradicional do bibliotecário como "organizador" da informação continua muito presente nas descrições das entrevistadas. Como se pode notar no trecho abaixo:

Ah, é fundamental né? Se as coisas não forem organizadas ninguém encontra. Tudo o que está nos catálogos é porque alguém colocou lá. Alguém tem que fazer essa parte de incluir. E eu gosto dessa parte, porque acho que se aprende muito. Tenho uma curiosidade intelectual bem desenvolvida, então todo o material que eu pego pra catalogar é um assunto novo, é uma coisa que me atrai (Entrevistada D, 2016).

Esses trechos das entrevistas permitem notar a coexistência de distintas percepções da atuação e da importância do bibliotecário, notando-se a utilização de termos como mediador, tutor e organizador. Entretanto, para Lankes essa noção de mediação precisa ser problematizada. Segundo esse autor: "precisamos começar a utilizar menos o termo mediador e mais o participante; o bibliotecário precisa 
estar junto, trabalhando com todos, sendo um personagem ativo" (2012, não paginado) e, para Resende:

Ao se definir como mediador, este profissional não se assume, de fato, como educador, a quem cabe formar leitores e formar indivíduos capazes de conhecer vias de acesso às informações, mas, sobretudo, capazes de selecionar e classificar estas informações, quanto à sua relevância, consistência e pertinência. (RESENDE, 2005, p. 100).

$\mathrm{Na}$ análise das entrevistas observou-se que para o grupo em estudo ainda se sobressai a imagem do bibliotecário como "mediador" de informação. Contudo, observa-se, aos poucos, um movimento de mudança que percebe o bibliotecário como um "educador" ou "tutor". No entanto, para que essa nova concepção possa evoluir e se estabelecer é necessário que os bibliotecários transcendam os limites físicos da biblioteca, a partir de uma posição de convencimento também fora desses limites, uma vez que as bibliotecas universitárias estão inseridas em uma instituição maior. No próximo tópico tratamos das narrativas das bibliotecárias quando questionadas sobre suas práticas e a relação com a cibercultura.

\subsection{Percepções sobre as práticas bibliotecárias em tempos de cibercultura}

No que se refere à questão - Como você percebe a prática do bibliotecário em tempos em que os usuários possuem acesso à internet? Notou-se uma tentativa de reafirmação da importância do bibliotecário como um agente "facilitador" no acesso à informação on-line. Papel este que, segundo a Entrevistada $A$, não se modificou ao longo do tempo, apenas se adaptou à inserção dos recursos tecnológicos:

Eu acho que a gente tem a função de facilitar né. A gente consegue ajudar, porque muita gente tem dúvidas de como pesquisar, como acessar, como recuperar. Eu acho que a gente entra como "facilitador", como uma ponte, porque são muitos incursos né, muitas coisas assim... Então, a gente consegue facilitar o acesso pro aluno e de certa forma como usar as tecnologias, eu acho que é isso (Entrevistada A, 2016).

Para Lankes (2012) a ideia de "facilitador" não abrange a complexidade das práticas realizadas nas bibliotecas. Segundo o autor, o bibliotecário deve ser mais do que um "facilitador", deve ser uma fonte de inspiração: 
Inspirar a comunidade parece que exige uma palavra mais "forte" que facilitar, algo do tipo "empoderar", "advogar" ou até mesmo "inspirar". Bibliotecas deveriam fazer tudo isso. Lembre-se que facilitar é apenas uma pequena parte de toda missão de "melhorar a sociedade facilitando a criação de conhecimento em suas comunidades". A palavra fundamental é "melhorar", o que significa que é algo ativo, que está sempre acontecendo. (LANKES, 2012, não paginado).

Essa concepção, além de defender um processo dinâmico para a atuação profissinal, busca desafiar o bibliotecário a ser pró-ativo e a antecipar-se aos usuários quanto ao conhecimento $e$ ao uso de determinadas fontes de informação on-line, o que talvez possa ser considerada uma justificativa para sua permanência no mercado de trabalho ou uma tentativa de preservar sua cultura profissional. No caso das entrevistas, percebe-se que as respostas apresentadas tiveram como base a perspectiva e a certeza de que os estudantes continuarão utilizando os serviços prestados pelas bibliotecas universitárias ou por seus bibliotecários. Assim, a habilidade do bibliotecário na eleição de fontes de informação confiáveis também fundamentou as definições sobre a importância deste profissional no contexto educacional.

Observando as considerações da Entrevistada D, nota-se uma preocupação com a posição do bibliotecário no contexto educacional. Para ela a postura pode ser considerada passiva no que se refere à instrução aos estudantes para a seleção e uso de fontes de informação adequadas, principalmente para aqueles em início de graduação:

"Então eu acho que quando isso acontece que tá no início do curso, bom... isso faz parte do processo. Agora, um aluno que chega no final do curso e vem pra biblioteca porque tá fazendo um TCC ou um trabalho mais importante e diz que não sabe dessas coisas, eu acho que a gente falhou. Em algum momento a biblioteca não conseguiu atingir essas pessoas. Passaram pelo curso sem que a biblioteca tenha conseguido fazer esse despertar para que... o mundo é mais do que o Google, né. Eu acho uma falha" (Entrevistada D, 2016).

Observou-se ainda nas respostas que as entrevistadas consideram fundamental a manutenção do espaço físico da biblioteca e, para isso, defenderam um movimento de divulgação dos serviços e dos espaços a fim de atrair os usuários.

Nesse contexto, há também a identificação de um público que não mais é frequente no ambiente físico da Biblioteca, os estudantes da PósGraduação: 
Nós não temos nada que os atraia para eles virem e ficarem aqui, porque todas as revistas que nós temos eles têm acesso da sala deles ou da sala de pesquisa. Esse aluno não vem mais" (Entrevistada D, 2016).

Entretanto, nota-se uma preocupação em restabelecer o contato com estes estudantes a partir da indicação de que a Biblioteca deve ir até eles:

Eu tenho impressão de que existe um público que a gente não tá atingindo, desses que não estão vindo aqui. E não adianta querer que eles venham, porque eles não virão. $O$ que nós não estamos conseguindo é fazer o contrário, ir até eles. E a gente está bem sentada esperando: 'Venham! Estou aqui esperando.' Não adianta, não vão vir, porque aquela época que eles vinham já foi (Entrevistada D, 2016).

Tal visão vai ao encontro das seguintes ideias de Lankes: "Você, bibliotecário, não deve esperar que todos vão à biblioteca. Vá até eles, esteja onde eles estão", ou ainda, "O bibliotecário precisa em alguns momentos deixar seu local de trabalho e atuar junto da comunidade" (2012, não paginado). É possível identificar também que não há apenas a preocupação em contatar os usuários que se afastaram do ambiente físico da Biblioteca, mas manter a frequência do público que mais a utiliza.

Em tempos de cibercultura, nota-se a necessidade de uma postura diferenciada do profissional bibliotecário que atua no contexto universitário. Entretanto, se percebe, nesse estudo, que novas concepções estão emergindo e, a partir delas, novas ações poderão ser colocadas em prática. Dois sentidos identificados nessa pesquisa revelam a transformação de uma concepção passiva sobre a atuação deste profissional em uma concepção mais ativa, principalmente com relação à interação com o usuário. Um refere-se à substituição da noção de "mediador" pelo de "educador". O outro sentido da mudança refere-se à substituição da postura de "esperar o usuário vir" para a de "ir até o usuário".

No que se refere às questões - Conte um pouco sobre sua prática profissional na Biblioteca. Quais mudanças você percebe em suas práticas ao longo do trabalho como bibliotecária - observou-se que as narrativas das práticas priorizaram as atividades de processamento técnico (organização dos acervos), serviço de referência (atendimento ao usuário) e de gestão de bibliotecas (planejamento). Porém, a atividade de processamento técnico obteve maior destaque dentre as narrativas tanto das bibliotecárias aposentadas quanto das bibliotecárias em atividade. No trecho a seguir, uma das bibliotecárias aposentadas relembra aspectos de como ocorria essa atividade no período inicial de sua atuação:

Em 14 de julho de 1966 eu comecei a trabalhar lá. Olha só, desdobrar fichas, (risos), tu nem sabe o que que é isso né (risos), pois chegava o livro era feita a ficha matriz e dali tu tinha que fazer igual, por título, por data, que a gente tinha, 
que era uma coisa tri legal que tinha lá na Biblioteca, porque por exemplo, eles queriam saber: quero saber os livros de 1966 que tem, então tu ia lá na gavetinha e dizia: olha são esses os livros que tem por assunto, obviamente também, então isso tudo... Esse trabalho nunca terminava, tava sempre atrasado né (Entrevistada H, 2016).

As narrativas das entrevistadas enfatizaram que as tradicionais atividades bibliotecárias, como processamento técnico (organização da informação), serviço de referência (atendimento ao usuário) e gestão da biblioteca continuam sendo executadas. Contudo, nota-se a existência de sentidos contraditórios nas narrativas, visto que algumas bibliotecárias consideraram que as práticas foram facilitadas pelas tecnologias e, nesse caso, teriam sido modificadas, enquanto outras ponderaram que as práticas não se modificaram, as ferramentas de trabalho é que foram evoluindo. Pode-se identificar essa dicotomia nos trechos abaixo:

O foco da busca, de acesso à informação não mudou. Eu acho que mudou foram as tecnologias como facilitadoras da nossa atividade. Mudou pra melhor, eu acho, com certeza (Entrevistada A, 2016).

A atividade não mudou, as ferramentas pra executar a atividade é que foram evoluindo, mas a atividade não mudou (Entrevistada D, 2016).

Na verdade, não vejo muita diferença nas práticas. O que mudou foi a tecnologia, novos softwares, novas facilidades assim... Mas a prática continua a mesma. Quer dizer tu recebe o documento, tem que catalogar. (Entrevistada D, 2016).

De acordo com as entrevistadas, as tecnologias de informação e comunicação possibilitaram aos bibliotecários maior agilidade e economia de tempo na realização das tarefas, assim como facilitaram a comunicação com outras instituições de ensino e pesquisa. Nas palavras da Entrevistada G:

"A transformação que houve foi muita." (Entrevistada G, 2016).

E, segundo a entrevistada C:

Pra mim fica a percepção de que mudou foi a estrutura de onde a informação está. Então, se antes nós usávamos as famigeradas fichinhas de papel que precisavam ser duplicadas 
diversas vezes, e que exigiam um trabalho braçal muito grande, hoje a gente tem isso transformado numa tecnologia que tu consegue inserindo os dados apenas uma vez, tu consegue resgatar todas aquelas informações. Então me parece que deu muito mais agilidade pra busca dessa informação, preservação até, com essas tecnologias. Mas mudou radicalmente, né. Antes a gente se preocupava se tinha sete espaços, duas linhas, eu até peguei isso na minha formação. (Entrevistada C, 2016).

Em outras narrativas a questão da velocidade de circulação das informações também foi mencionada, principalmente no que se refere à atividade de comutação bibliográfica:

Em minutos eu já vejo qual biblioteca tem né, pelo meu computador e já encaminho digitalmente, porque aí eu entro no sistema, preencho o formulário e já envio, a biblioteca que tem já vai visualizar isso, já vai escanear esse documento e já vai mandar, muitas vezes, inúmeras vezes eu já tenho o artigo no mesmo dia. Às vezes vai demorar assim, o tempo que a pessoa vai atender né. Mas antigamente eu cheguei a pegar esse mesmo serviço, num outro momento em que era muito mais lento, demorava meses, às vezes dois meses pra chegar um artigo. (Entrevistada E, 2016).

Observou-se ainda a exaltação às contribuições tecnológicas para as atividades bibliotecárias:

Essas coisas tecnológicas são boas né, vem só facilitar nosso trabalho. Imagina alfabetar todas aquelas fichas e, quando era alfabetada errada, às vezes se alfabetava errado, vinha a próxima, quando tu via era um monte de ficha alfabetada errado. A gente tinha os auxiliares que nos ajudavam. Essas coisas vieram a melhorar muito né, eu acho (Entrevistada G, 2016).

Antigamente era bastante difícil fazer o cruzamento dos assuntos em papel, porque às vezes tu queria 0 assunto cruzado, tinha que ver o que tinha aqui e ali, e ver o que coincidia. Não era fácil fazer o levantamento bibliográfico quando era em papel (Entrevistada G, 2016).

Notou-se, portanto, um balanço favorável às mudanças advindas do uso de novas tecnologias, tanto para as atividades técnicas cotidianas quanto para a disponibilização e recuperação da informação e para a divulgação dos acervos. Tais constatações, no entanto, não deixam de perceber que essa mesma tecnologia, base da cibercultura, tem contribuído significativamente para o afastamento de parte dos usuários 
do ambiente físico da Biblioteca, assim como, exige maior pró-atividade dos bibliotecários.

Essas avaliações ensejaram algumas modificações na atuação do grupo de bibliotecárias, delas decorreu, por exemplo, a realização da primeira atividade coletiva de "educação de usuários", em 2016, voltada ao curso de Medicina e a criação de uma disciplina optativa ministrada pelas bibliotecárias, dois anos depois, em 2018. Entendendo-se nesse contexto por "educação de usuário" a definição de Dias: "[...] o processo pelo qual o usuário interioriza comportamentos adequados em relação ao uso da biblioteca e desenvolve habilidades de interação permanente com sistemas de informação" (2004, p. 38).

No que se refere à graduação em Nutrição, há algum tempo os professores já disponibilizavam horas/aula semestralmente para as bibliotecárias realizarem atividades com os discentes. Tal abertura pode estar relacionada ao fato de que no curso de Nutrição os discentes necessitam realizar um Trabalho de Conclusão de Curso (TCC) e, portanto, demandam mais informações sobre fontes de informação, normalização e apresentação de trabalhos acadêmicos.

\section{Considerações finais}

Com base na pesquisa, foi possível perceber que as concepções e sentidos analisados, apresentados pelos profissionais bibliotecários, ainda estão bastante vinculados à ideia de uma biblioteca universitária nos modelos tradicionais e suas práticas relacionadas às questões técnicas da profissão. Tais concepções e sentidos, além de influenciarem suas práticas atuais, também interferem em suas perspectivas com relação ao futuro de sua atuação e das configurações de biblioteca universitária. As ênfases dadas às questões de cunho técnico suscitaram novas indagações, dentre elas: Será que a formação acadêmica do bibliotecário está privilegiando as questões técnicas a ponto de produzir certo anacronismo profissional frente às transformações impostas pela cibercultura?

Nas narrativas percebe-se também uma necessidade de reafirmação e melhora da imagem profissional a partir do uso de expressões como: "ser cara de pau", "ser pró-ativo" ou "vender o próprio serviço", embora considerando que as bibliotecárias, através de suas memórias, demonstram satisfação e sentimento de valorização com relação ao seu trabalho, pois apresentam suas experiências profissionais de forma positiva e, por vezes, idealizada.

A importância do bibliotecário no contexto acadêmico também é evidenciada, a partir de sua atuação como "mediador", "organizador", "investigador" e "facilitador", enfatizando a parte técnica da profissão. Mas há igualmente a indicação de que o bibliotecário deve tornar visível sua importância, juntamente com os serviços prestados pela Biblioteca. O que também pode configurar uma tentativa de mudança da imagem profissional.

Já a ideia de manter o espaço tradicional é evidenciada a partir da indicação de que é necessário que o bibliotecário desenvolva habilidades 
interpessoais e comunicacionais a fim de relacionar-se adequadamente com o público que atende. Ou seja, há uma preocupação em cativar o usuário para o uso do espaço físico da Biblioteca. Observaram-se ainda sentidos contraditórios sobre a alteração das práticas bibliotecárias a partir dos avanços tecnológicos e da cibercultura: algumas entrevistadas consideram que as práticas se modificaram enquanto outras entendem que não houve mudanças nas práticas, apenas se alteraram os instrumentos de trabalho.

Entretanto, com relação aos impactos causados pela cibercultura, as entrevistadas entenderam que houve expressiva alteração quanto ao uso da Biblioteca, principalmente com o afastamento de estudantes dos cursos de Pós-Graduação e de professores. Essa mudança foi atribuida ao fato de que os materiais que anteriormente eram unicamente acessados dentro da Biblioteca hoje circulam em meio digital e em rede.

Quanto à atuação do bibliotecário no cenário acadêmico, nota-se nas narrativas, que o sentido de "mediador" passa a dar espaço ao sentido de "educador", assim como a ação de "esperar o usuário" passa a dar lugar à de "buscar o usuário". Tal movimento de mudança de sentido demonstra uma inquietação com relação ao futuro da Biblioteca e da atuação do bibliotecário. O que pode indicar também um desejo de manutenção do ambiente físico das bibliotecas e de permanência no mercado de trabalho.

Contudo, o sentido de "mediação" utilizado nas narrativas, ou seja, aquele que apenas disponibiliza a informação, fazendo um papel de "ponte" entre informação e usuário, talvez deva ser repensado na perspectiva de uma "mediação pedagógica", caso se tenha interesse em avançar no aspecto educativo da profissão de bibliotecário.

Por fim, se compararmos as narrativas das entrevistadas com os estudos teóricos da área veremos que as concepções apresentadas pouco se diferem da literatura atual, ou até mesmo da de décadas anteriores, ao defender a necessidade de o bibliotecário ser pró-ativo e de divulgar o seu trabalho. Observa-se ainda a postura de que o bibliotecário deve buscar continuamente "melhorar a imagem" da profissão e colocar fim aos estereótipos pejorativos relacionados a ela.

\section{Referências}

BELLUZZO, Regina Célia Baptista. Competências na era digital: desafios tangíveis para bibliotecários e educadores. Educação Temática Digital, Campinas, v. 6, n. 2, p.30-50, jun. 2005.

CRESTANA, Maria Fazanelli. Discurso de bibliotecárias a respeito de suas profissões na área médica. 2002. Dissertação (Mestrado em Administração Hospitalar) - Faculdade de Saúde Pública, Universidade de São Paulo, São Paulo, 2002. Disponível em: http://www.teses.usp.br/teses/disponiveis/6/6131/tde-27062003121133/pt-br.php. Acesso em: 7 jan. 2017. 
CUNHA, Murilo Bastos da. Construindo o futuro: a biblioteca universitária brasileira em 2010. Ciência da Informação, Brasília, v. 29, n. 1, p. 7189, jan./abr. 2000. Disponível em: http://revista.ibict.br/ciinf/article/view/901/938. Acesso em: 27 ago. 2019.

DIAS, M. M. K.; PIRES, D. Usos e usuários da informação. São Carlos: EDUFSCAR, 2004. (Série Apontamentos).

DRABENSTOTT, Karen M.; BURMAN, Celeste M. Revisão analítica da biblioteca do futuro. Ciência da Informação, Brasília, v. 26, n. 2, maio/ago. $1997 . \quad$ Disponível em: http://www.scielo.br/scielo.php?script=sci_arttext\&pid=S010019651997000200012. Acesso em: 7 jan. 2017.

FERRAREZI, Ludmila; ROMÃO, Lucília Maria Sousa. Sentidos de biblioteca escolar no discurso da ciência da informação. Informação e Sociedade: Estudos, João Pessoa, v. 18, n. 3, p. 29-44, set./dez. 2008.

FERRAREZI, Ludmila; ROMÃO, Lucília Maria Sousa. Certos sentidos de biblioteca escolar: efeitos de repetição e deslocamento. Linguagem em (Dis)curso, Tubarão, SC, v. 13, n. 1, p. 35-64, jan./abr. 2013.

FRAGA, Nádia Elôina Barcelos; MATTOS, Carla Erler; CASSA, Gabriela de Almeida. O marketing profissional e suas interfaces: a valorização do bibliotecário em questão. Perspectivas em Ciência da Informação, Belo Horizonte, v. 13, n. 2, p. 148-167, maio/ago. 2008. Disponível em: http://portaldeperiodicos.eci.ufmg.br/index.php/pci/article/view/ 136/490. Acesso em: 3 jan. 2017.

GRAZZIOTIN, Luciane Sgarbi S.; ALMEIDA, Dóris Bittencourt. Romagem do tempo e recantos da memória: reflexões metodológicas sobre história oral. São Leopoldo: Oikos, 2012.

HASSEN, Maria de Nazareth Agra; RIGATTO, Mário. Fogos de bengala nos céus de Porto Alegre: a Faculdade de Medicina faz 100 anos. Porto Alegre: Tomo Editorial, 1998. 239p.

LANKES, David. Expect more: demanding better libraries for today's complex word. [S.I.: S.n.], 2012. Disponível em: https://davidlankes.org/?page_id=8274. Acesso em: 15 jan. 2017.

LARROSA, Jorge. Notas sobre narrativa e identidade. In: ABRAHÃO, Maria Helena Menna Barreto (org.). A aventura (auto)biográfica: teoria e empiria. Porto Alegre: EDIPUCRS, 2004. p. 11-22.

NITSCHKE, Angela Morel. Representações Sociais e práticas profissionais na sociedade da informação: estudo com usuários de bibliotecas universitárias de Porto Alegre. 2008. 94f. Dissertação (Mestrado em Comunicação e Informação), Faculdade de Biblioteconomia e Comunicação, Universidade Federal do Rio Grande do Sul, Porto Alegre, 2008. 
NUNES, Martha Suzana Cabral; CARVALHO, Kátia de. As bibliotecas universitárias em perspectiva histórica: a caminho do desenvolvimento durável. Perspectivas em Ciência da Informação, Belo Horizonte, v. 21, n. 1 , p. 173-193, jan./mar. 2016. Disponível em: http://www.scielo.br/pdf/pci/v21n1/1413-9936-pci-21-01-00173.pdf.

Acesso em: 27 ago. 2019

RESENDE, Érica dos Santos. Representações sociais de bibliotecário: onde o antigo e o novo se confrontam. 2005. 114f. Dissertação (Mestrado em Educação) - Universidade Estácio de Sá, Rio de Janeiro, 2005.

SANTAELLA, Lúcia. Navegar no ciberespaço: o perfil cognitivo do leitor imersivo. São Paulo: Paulus, 2004. 191 p.

ZAGO, Nadir. A entrevista e seu processo de construção: reflexões com base na experiência prática de pesquisa. In: ZAGO, Nadir; CARVALHO, Maria Pinto de; VILELA, Rita Amélia Teixeira (org.) Itinerários de pesquisa: perspectivas qualitativas em Sociologia da Educação. Rio de Janeiro: DP\&A, 2003. p. 287-309. 